\title{
SHOULD HEALTHCARE PROVIDERS IN THE VA HEALTHCARE SYSTEM TELECOMMUTE?
}

\begin{tabular}{|c|c|}
\hline $\begin{array}{l}\text { Michelle Bergman } \\
\text { Brittany Miller } \\
\text { Vida Passero } \\
\text { Enrique } \mathrm{Mu}^{1}\end{array}$ & $\begin{array}{l}\text { mlbergman@live.carlow.edu } \\
\text { blmiller@live.carlow.edu } \\
\text { vapassero@,live.carlow.edu } \\
\text { emu@,carlow.edu }\end{array}$ \\
\hline
\end{tabular}

\begin{abstract}
This paper proposal will examine, using an AHP approach, the decision behind whether or not Veterans Affairs (VA) healthcare providers, namely physicians, should telecommute as part of the clinical video telehealth visit.

Keywords: Telehealth, Telecommuting.

\section{Introduction}

Clinical video telehealth already exists in the VA. Currently during the clinic video telehealth visit, the patient is at home or in a satellite clinic and the healthcare provider consultant is at the main hospital or clinic. As a result, patients overcome access barriers and do not have to drive to VA Pittsburgh to see their subspecialty provider for some, but not all, diseases.
\end{abstract}

\section{Literature Review}

For this decision, telecommuting literature as well as VA experts' judgments will be considered.

\section{Hypotheses/Objectives}

In this decision approach, the goal is to examine whether healthcare providers, namely physicians, could be at home instead of on-site at the hospital or clinic while conducting the clinical video telehealth visit. The analysis will consider different stakeholders' perspectives..

\section{Research Design/Methodology}

1 Corresponding Co-author and faculty sponsor. All participants are affiliated with Carlow University, Pittsburgh, PA. USA. 
Bergman, Miller, Passero, Mu - VA Telecommuting: International Symposium of the Analytic Hierarchy Process 2016, London, U.K.

AHP Stakeholder analysis will be used to analyze the decision. In particular, the perspectives corresponding to the VA hospital administration, VA healthcare providers and VA patients will be considered.

\section{Data/Model Analysis}

Three AHP models will be used. Each corresponding to each of the perspectives.

\section{Limitations}

Given that this study is currently under development, we cannot determine any specific limitation yet.

\section{Conclusions}

Our analysis should allow us to conclude whether telecommuting for VA healthcare providers should be implemented or not.

\section{Key References}

- $\quad$ Mu, E., Wormer, S., Foizey, R., Baxton, B. and Vehec, M. (2012). Group Modeling and Integration of Multiple Perspectives in the Functional Selection of a New Technology: The Case of a Next Generation Electronic Portfolio System. Journal of Multicriteria Decision Analysis, Vol 19, Issue 1-2, 15-31.

- Mu, E. and Pereyra-Rojas, M. (forthcoming 2016). Practical decision making: An introduction to the Analytic Hierarchy Process using Super Decisions 2.2. Springer: N.Y.

- Saaty, T. L. (1980). The Analytic Hierarchy Process: Planning, Priority Setting, Resource Allocation. McGraw Hill: New York, NY.

\section{Appendices}

n/a. 